\title{
Vertebral fracture as risk factors for self-harm: A retrospective cohort study
}

James Prior ( $\boldsymbol{\nabla}$ j.a.prior@keele.ac.uk)

Keele University

Fay Crawford-Manning

Keele University

Rebecca Whittle

Keele University

Alyshah Abdul-Sultan

Keele University

Carolyn Chew-Graham

Keele University

Sara Muller

Keele University

Tom Shepherd

Keele University

Athula Sumathipala

Keele University

Christian Mallen

Keele University

Zoe Paskins

Keele University

\section{Research Article}

Keywords: Vertebral fracture, self-harm, primary care

Posted Date: November 30th, 2020

DOI: https://doi.org/10.21203/rs.3.rs-106349/v1

License: (9) This work is licensed under a Creative Commons Attribution 4.0 International License. Read Full License 


\section{Abstract}

\section{Background}

The prevention of self-harm is an international public health priority, It is vital to identify at-risk populations, particularly as self-harm is a risk factor for suicide. This study aims to examine the risk of self-harm in people with vertebral fractures

\section{Methods}

Retrospective cohort study using data from the Clinical Practice Research Datalink. Patients with vertebral fracture were identified and matched to patients without fracture by age and gender. Incident self-harm was defined by medical record codes following vertebral fracture. Overall incidence rates (per 10,000 person-years (PY)) were reported. Cox regression analysis determined risk (hazard ratios (HR), 95\% confidence interval (CI)) of self-harm compared to the matched unexposed cohort. Initial crude analysis was subsequently adjusted and stratified by age and gender.

\section{$\underline{\text { Results }}$}

The number of cases of vertebral fracture was 16,293 , with a matched unexposed cohort of the same size. Patients were predominantly female (70.1\%), mean age was 74 years. Overall incidence of self-harm in the cohort with vertebral fracture was $12.2(10.1,14.8) / 10,000$ PY. There was an initial crude association between vertebral fracture and self-harm, which remained after adjustment (HR $2.4(95 \% \mathrm{Cl}$ 1.5, 3.6).Greatest risk of self-harm was found in those with vertebral fractures who were younger (3.2(1.8, $5.7))$ and male $(3.9(1.8,8.5))$.

\section{Conclusions}

Primary care patients with vertebral fracture are at increased risk of self-harm compared to people without these fractures. Younger, male patients appear to be at greatest risk of self-harm. Clinicians need to be aware of the potential for self-harm in this patient group.

\section{Introduction}

The prevention of self-harm is an international public health priority [1, 2], but in the UK, here has been an increase in presentations of self-harm to primary care for both men and women[2]. It is vital to identify atrisk populations, particularly as self-harm is a risk factor for suicide [3]. The World Health Organisation (WHO) have recommended that non-specialist healthcare professionals could evaluate the self-harm potential of patients who present with symptoms of chronic pain and/or depression [4]. Mental ill-health, notably a history of a depressive disorders, is a strong risk factor for self-harm [5], and although pain is on the causal pathway for depression, pain and more specifically back pain, is also an independent risk factor for self-harm $[6,7]$. 
Osteoporotic fractures are commonly associated with chronic pain, particularly vertebral fractures[8]. Vertebral fractures, which may result in physical impairments such as kyphosis and height loss, have also been linked with psychological sequelae including depression and anxiety [9], with comorbid depression also being associated with osteoporosis itself [10]. As many as $20 \%$ of the elderly population are affected by vertebral fractures, which have a well-documented association with reduced quality of life and increased disability [11, 12], which have been reported as motivators for self-harm in older adults [13]. Furthermore, osteoporosis shares several risk factors with depression, such as smoking, drinking and immobility [14].

We have recently reported increased risk of self-harm in people with fibromyalgia, rheumatoid arthritis and osteoarthritis [15], and similarly, the risk of self-harm has previously been examined in osteoporosis and back pain. Using CPRD data, Webb et al., found increased risk of self-harm in females, but not males, with osteoporosis, and in both genders with back pain [6]. They did not however, look at the vertebral fracture population, meaning that risk of self-harm in people with vertebral fractures is still unknown.

Our aim was to examine the risk of self-harm in patients with vertebral fractures in a primary care population and to examine the role of age and gender on such risk.

\section{Patients And Methods}

\section{Study design}

We undertook a matched retrospective cohort study using Read-coded patient data (the clinical coding system used in UK primary care) from the Clinical Practice Research Datalink (CPRD), a database of anonymised primary care records covering around $7 \%$ of the UK population [16]. This provides both coded consultation and prescription data and is representative of the UK population, with regards to age, sex and ethnicity [16].

\section{Study Population}

We identified patients aged $\geq 18$ years with vertebral fracture between 1 st January 1990 and 31 st December 2016. This cohort was identified by specified Read codes, based on and refined from an internal code list repository (www.keele.ac.uk/mrr) and assigned an index date corresponding to the date of their diagnosis.

A matched unexposed cohort was constructed as a comparison cohort. The unexposed cohort included individuals without a previous coded diagnosis of vertebral fracture, but no further exclusion was made based on the presence of other chronic disease, including osteoporosis. Cases were grouped by 10-year age range and gender and then within these categories' frequency matched to unexposed patients. Each control was assigned a pseudo-index date, generated at random from between their 18th birthday and the end of the study. All individuals were subsequently examined for a self-harm Read code, based on the Read code list used in previous CPRD research [2] (Code list available at www.keele.ac.uk/mrr upon 
request). Patients with a self-harm code prior to index date were excluded and incidence based only on the first self-harm code reported post vertebral fracture.

\section{Statistical Analysis}

Descriptive statistics were initially used to characterise the vertebral fracture cohort, including age, gender, practice-level deprivation, BMI, smoking status, alcohol consumption and previous diagnosis for anxiety and/or depression (the latter four defined by the closest value recorded before the index date). The incidence rate of self-harm per 10,000 person-years (PY) was determined for vertebral fracture from 01/01/1990 to $31 / 12 / 2016$. Patients contributed data after the latest of three events: (1) the study start date, (2) the date they registered at a participating practice, plus 6 months or (3) the date at which the practice was adjudged to reach internal quality standards, known as the 'up-to-standard' date.

Using Cox proportional-hazards regression analysis over the full time-period (1990-2016), crude hazard ratios (HR) were initially reported with $95 \%$ confidence intervals (Cls) to examine the association between the presence of vertebral fracture and the subsequent incidence of self-harm compared to the matched unexposed cohort. Adjusted analysis was then undertaken, accounting for age, gender, practice-level deprivation, BMI, smoking status, alcohol consumption, anxiety and depression. Cases with missing data for smoking, BMI and alcohol consumption were included within analysis using a missing category approach. Imputation was not considered sensible in this case, as data were unlikely to be missing at random $[17,18]$. Proportionality of hazards was examined for each model using Schoenfeld's residuals. Where variables showed evidence of non-proportionality, they were included as time varying covariates. Further analyses were conducted, stratifying by median age of the exposed cohort and gender. We defined our dichotomized age subgroups as "younger" ( $<76.3$ years) or "older" ( $>76.3$ years) patients. Data were analyzed with Stata software (version 15.1, StataCorp, College Station, TX, USA). A two-sided $p$-value $<0.05$ was considered for statistical significance.

This study is based in part on data from the CPRD, obtained under license from the UK Medicines and Healthcare products Regulatory Agency (MHRA). The data is from patients who have provided informed consent and collected by the NHS as part of their care and support. This study was approved by the CPRD Independent Scientific Advisory Committee (reference number 18_018R3) prior to release of requested data and has adhered to their guidelines.

\section{Results}

\section{Sample characteristics}

The number of cases of vertebral fracture was 16,293, with a matched unexposed cohort of the same size. Patients were predominantly female $(70.1 \%)$ and the mean age was 74.8 in the exposed cohort (similar in the unexposed cohorts). The prevalence of anxiety and depression in the exposed cohort was approximately double that seen in the unexposed (Table 1). 
Table 1: Characteristic of patients with vertebral fracture and their matched cohorts (1990-2016)

Incidence and risk of self-harm in Vertebral fractures

Overall incidence of self-harm in the cohort with vertebral fractures was $12.2(95 \% \mathrm{Cl} 10.1,14.8)$ per 10,000 PY. When stratified by age, the incidence was $13.4(95 \% \mathrm{Cl} 10.4,17.1)$ in those $<76.3$ years and 10.8 $(95 \% \mathrm{Cl} 8.0,14.7)$ in those $>76.3$ years. When stratified for gender, incidence was $17.7(95 \% \mathrm{Cl} 12.6,23.2)$ and $10.3(95 \% \mathrm{Cl} 8.1,13.2)$ for males and females respectively (Table 2$)$.

Table 2: Risk of self-harm associated with vertebral fracture

When associations were examined, there was a significant crude association between vertebral fracture (HR $2.3(95 \% \mathrm{Cl} 1.7,3.3)$ ) and subsequent self-harm compared to having no recorded vertebral fracture. This association was retained after adjustment (HR $2.4(95 \% \mathrm{Cl} 1.5,3.6)$ (Table 2). After stratifying at the median age, we found there to be a marked difference between the crude risk of self-harm across the younger $(<76.3$ years) and older ( $>76.3$ years) strata for the vertebral fractures cohort (HR $3.1(95 \% \mathrm{Cl} 1.9$, 4.8) and HR $1.7(95 \% \mathrm{Cl} 1.0,2.7)$ respectively). This difference in risk of self-harm between the younger and older groups became greater after adjustment and a significant association was only retained for the younger cohort (<76.3years: HR $3.1(95 \% \mathrm{Cl} 1.9,4.8)$, > 76.3 years: $(\mathrm{HR} 1.7(95 \% \mathrm{Cl} 0.9,3.3))$.

Crude analysis found males with vertebral fractures to be almost four times more likely to self-harm compared to those without a previous vertebral fractures $(\mathrm{HR} 4.0(95 \% \mathrm{Cl} 2.1,7.7))$ and females to be almost two times as likely to self-harm (HR $1.8(95 \% \mathrm{Cl} 1.2,2.7))$. These significant associations were altered little by adjustment, (Males: HR $3.9(95 \% \mathrm{Cl} 1.8,8.5)$; Females HR $1.9(95 \% \mathrm{Cl} 1.1,3.2))$ and remained statistically significant (Table 2 ).

\section{Discussion}

Although the absolute incidence of self-harm was low, we found that primary care patients with vertebral fractures are at increased risk of self-harm compared to matched patients without fractures. Age and gender were also found to be effect modifiers, with the younger ( $<76.3$ years) and male strata showing an increased risk of self-harm in those with vertebral fractures.

Overall, in this study, male patients with vertebral fractures showed the greatest risk of self-harm with a 4fold increase compared to an age matched unexposed cohort. This contrasts with the trend for higher rates of self-harm seen in females in the general population, and the previous study examining risk in osteoporosis $[2,6]$. This may be explained by differences in the experiences and perceptions of males with vertebral fractures, or in clinical risk factors. Males who display low bone density, and increased fracture risk, often have an underlying causes such as medication use (steroids), hormone related conditions such as hypogonadism or lifestyle behaviours, such as smoking [17-19]. The presence of multimorbidity is associated with higher instances of self-harm and mental illness diagnosis, whilst 
behavioral factors such as smoking are risk factors for depression in and of themselves [20, 21]. Further, conditions such as hypogonadism which can increase fracture risk are linked themselves, with mental illhealth in men [22]. In a study exploring males experience of having osteoporotic vertebral fractures, osteoporosis was perceived as an old women's disease [23]. A gendered societal view of fractures relating to osteoporosis/low bone mineral density (BMD) can cause a threat to masculinity, leading to avoidance of seeking help or consulting healthcare practitioners [23-25], disbelief and difficulty discussing with others. This relates to research on males with chronic pain who reported that they avoided seeking health care, and expectations of being 'stronger' or more 'able to cope' were prevalent in those who self-harmed [26]. Furthermore, men can experience delayed diagnosis and treatment when it comes to osteoporosis, due to health care professional knowledge and gender differences in licensing of anti-osteoporotic medications [27] with males finding this "depressing" and "frustrating" [23].

Age contributed to the risk of self-harm, as those under the age of 76 with vertebral fractures were found to be three times more likely to self-harm as those in the matched population. Webb et al., similarly reported significant odds ratios in those $<60$ years with osteoporosis, as well as for cancer, coronary heart disease, stroke, and COPD [6]. Vertebral fractures are known to cause pain which is a risk factor in and of itself for self-harm [7], and vertebral fractures have been linked with decreases in health-related quality of life, loss of independence and low self-esteem and social problems [28-30].

\section{Strengths And Limitations}

This is the first study to examine vertebral fracture as a risk factor for incident self-harm. Our use of a large UK primary care dataset has allowed us to examine the incidence of self-harm as well as examine the role of age and gender. The accuracy of vertebral fracture codes has previously been validated [31] and our analysis also takes account of clinically recorded depression, a key risk factor for self-harm.

Several limitations to our work do need to be considered. First, our methods do not facilitate the identification of people with uncoded vertebral fractures. Vertebral fractures are often asymptomatic or undiagnosed and do not come to clinical attention [32], with one study reporting $80 \%$ of women with vertebral fracture being undiagnosed post radiographic investigation. Although the majority of vertebral fractures are likely to be a result of low trauma in this age group, the degree of trauma is not recorded. We have also not addressed the question of risk of self-harm in people with osteoporosis and/or other types of fragility fracture; osteoporosis is known to be poorly coded in CPRD with $<30 \%$ of those receiving osteoporosis medication having an osteoporotic code [33] and we hypothesized that of all the fragility fractures, vertebral fractures were more likely to be associated with chronic pain and therefore self-harm risk. We were not able to examine mechanisms in this study; for example, pain is likely to be a key contributory factor in the risk of self-harm [27]; however, it could not be determined from consultation record data. Furthermore, it remains unclear to what extent use of medications and treatments influence the risk of self-harm. Our original intention within this analysis had also been to examine year-on-year incidence and breakdown the age strata as well, as the younger/older strata are wide age groups, but numbers were too small for such analysis. We also found large proportions of missing data for BMI, 
smoking and alcohol consumption within the CPRD dataset, particularly in the unexposed patients. As such data is not "missing at random", we were unable to impute these missing values. However, we included missing data as a separate category in our models and reported the extent of missing data in descriptive tables to ensure transparency.

\section{Conclusion}

Although the absolute incidence is low, people with vertebral fractures have increased risk of self-harm compared to matched unexposed patients. Both age and gender are strong effect modifiers, with males and the younger strata being at increased risk. Further work is needed to explore the mechanisms of this association and develop appropriate interventions. In the meantime, healthcare professionals need to be vigilant, explore mood, assess risk, and offer appropriate support, management and referrals and signposting especially to younger people and males with vertebral fractures.

\section{Abbreviations}

CPRD - Clinical Practice Research Datalink

BMI- Body Mass Index

PY- Person Years

HR- Hazard Ratio

Cl- Confidence Interval

BMD- Bone Mineral Density

COPD- Chronic Obstructive Pulmonary Disease

\section{Declarations}

\section{Ethics Approval and consent to participate}

This study is based in part on data from the CPRD, obtained under license from the UK Medicines and Healthcare products Regulatory Agency (MHRA). The data is from patients who have provided informed consent and collected by the NHS as part of their care and support. This study was approved by the CPRD Independent Scientific Advisory Committee (reference number 18_018R3) prior to release of requested data and has adhered to their guidelines.

Consent for publication

Not applicable 
This study is based in part on data from the Clinical Practice Research Datalink obtained under license from the UK Medicines and Healthcare products Regulatory Agency. The data is provided by patients and collected by the NHS as part of their care and support. The interpretation and conclusions contained in this study are those of the author/s alone.

The data that support the findings of this study are available from CPRD, but restrictions apply to the availability of these data, which were used under license for the current study, and so are not publicly available. Data are however available from the authors upon reasonable request and with permission of CPRD.

The copyright of the morbidity definitions lists (@2014) used in this publication is owned by Keele University, the development of which was supported by the Primary Care Research Consortium. The authors would like to acknowledge Keele University's Prognosis and Consultation Epidemiology Research Group who have given us permission to utilise the morbidity definitions (@2014). For access/details relating to the morbidity definitions lists (@2014) please go to www.keele.ac.uk/mrr

\section{Competing interests}

James A. Prior, Fay Crawford-Manning, Rebecca Whittle, Alyshah Abdul-Sultan, Carolyn A. Chew-Graham, Sara Muller, Tom A. Shepherd, Athula Sumathipala, Christian D. Mallen and Zoe Paskins declare that they have no conflict of interest.

This study was funded by the National Institute for Health Research (NIHR) School for Primary Care Research (Funding Round 13, Grant Reference 349) and supported by the National Institute for Health Research (NIHR) Applied Research Centre (ARC) West Midlands. The views expressed are those of the author(s) and not necessarily those of the NIHR or the Department of Health and Social Care.

CDM is funded by the NIHR Applied Research Collaboration (ARC) West Midlands, the NIHR School for Primary Care Research and a NIHR Research Professorship in General Practice (NIHR-RP-2014-04-026). ZP is funded by the NIHR [Clinician Scientist Award (CS-2018-18-ST2-010)/NIHR Academy]. FCM is part funded by the NIHR Clinical Research Network Scholar Programme. CCG is part funded by NIHR ARC West Midlands. The study sponsors had no role in study design; in the collection, analysis, and interpretation of data; in the writing of the report; and in the decision to submit the paper for publication.

\section{$\underline{\text { Authors' contributions }}$}

JAP developed the initial project idea, the acquisition of funding, over-saw study design and analysis. ZP contributed to initial study idea, was a funding co-applicant and involved in overall study design. RW was a funding co-applicant, curated the data and conducted analysis. AAS was a funding co-applicant and supported RW in data curation. CCG was contributed to development of study idea, and acquisition of funding. SM \& RB provided support to JAP in undertaking data analysis. TS and AS were co-applicants in 
the funding application and CDM was involved in development of project idea, the funding application and overall study design. FCM contributed to the interpretation of the data and manuscript development. All authors were involved in manuscript writing, have read, and approved the final version.

\section{Acknowledgements}

Not applicable

\section{References}

1. World Health Organization (2016) World health statistics 2016 - monitoring health for the SDG's. sustainable development goals.

2. Carr MJ, Ashcroft DM, Kontopantelis E, Awenat Y, Cooper J, Chew-Graham C, Kapur N, Webb RT (2016) The epidemiology of self-harm in a UK-wide primary care patient cohort, 2001-2013. BMC Psychiatry 16:53 DOI 10.1186/s12888-016-0753-5

3. B R, A H, P L, D T (2016) Suicide risk after nonfatal self-harm: a national cohort study, 2000-2008. J Clin Psychiatry 77:240-6 DOI 10.4088/jcp.14m09453

4. World Health Organisation (2015) Assessment for self harm/suicide in persons with priority mental, neurological and substance use disorders [homepage on the Internet]. 2020

5. Fliege H, Lee J, Grimm A, Klapp BF (2009) Risk factors and correlates of deliberate self-harm behavior: a systematic review. J Psychosom Res 66:477-93 DOI 10.1016/j.jpsychores.2008.10.013

6. Webb RT, Kontopantelis E, Doran T, Qin P, Creed F, Kapur N (2012) Risk of self-harm in physically ill patients in UK primary care. Journal of Psychosomatic Research. Journal of Psychosomatic Research 73:92-7

7. Theodoulou M, Harriss L, Hawton K, Bass C (2005) Pain and deliberate self-harm: an important association. J Psychosom Res 58:317-20 DOI 10.1016/j.jpsychores.2004.10.004

8. National Osteoporosis Society (2014) Life with osteoporosis: the untold story. Key findings from research into the realities of life with osteoporosis.

9. Gold DT (2001) The nonskeletal consequences of osteoporotic fractures. Psychologic and social outcomes. Rheum Dis Clin North Am 27:255-62 DOI 10.1016/s0889-857x(05)70197-6

10. Cizza G, Primma S, Coyle M, Gourgiotis L, Csako G (2010) Depression and osteoporosis: a research synthesis with meta-analysis. Horm Metab Res 42:467-82 DOI 10.1055/s-0030-1252020

11. WHO Scientific Group (2003) The burden of musculoskeletal conditions at the start of the new millenium. Institutional Repository for Information Sharing :1-218 
12. Cauley JA, Thompson DE, Ensrud KC, Scott JC, Black D (2000) Risk of mortality following clinical fractures. Osteoporos Int 11:556-61 DOI 10.1007/s001980070075

13. Troya M, Babatunde OO, Polidano K, Bartlam B, McCloskey E, Dikomitis L, Chew-Graham CA (2019) Self-harm in older adults: a systematic review. British Journal of Psychiatry 214:186-200

14. Clarke DM, Currie KC (2009) Depression, anxiety and their relationship with chronic diseases: a review of the epidemiology, risk and treatment evidence. Med J Aust 190:54 DOI cla10974_fm [pii]

15. Prior JA, Paskins Z, Whittle R, Abdul-Sultan A, Chew-Graham CA, Muller S, Bajpai R, Shepherd TA, Sumathipala A, Mallen CD (2020) Rheumatological conditions as risk factors for self-harm: A retrospective cohort study. Arthritis Care \& Research n/a DOI 10.1002/acr.24345

16. Hahn C, Oh JH, Joo S, Jeong J, Chae J, Lee C, Kim T (2017) Association between mental health status and bone mineral density: Analysis of the 2008-2010 Korea national health and nutrition examination survey. PLoS One 12 DOI 10.1371/journal.pone.0187425

17. Briot K, Roux C (2015) Glucocorticoid-induced osteoporosis. RMD Open 1:e000014 DOI 10.1136/rmdopen-2014-000014

18. Golds G, Houdek D, Arnason T (2017) Male Hypogonadism and Osteoporosis: The Effects, Clinical Consequences, and Treatment of Testosterone Deficiency in Bone Health. International Journal of Endocrinology 2017:e4602129 DOI https://doi.org/10.1155/2017/4602129

19. Izumotani K, Hagiwara S, Izumotani T, Miki T, Morii H, Nishizaw Y (2003) Risk factors for osteoporosis in men. Journal of Bone and Mineral Metabolism 21:86-90

20. Morgan C, Webb RT, Carr MJ, Kontopantelis E, Chew-Graham CA, Kapur N, Ashcroft DM (2018) Selfharm in a primary care cohort of older people: incidence, clinical management, and risk of suicide and other causes of death. The Lancet Psychiatry 5:905-12 DOI 10.1016/S2215-0366(18)30348-1

21. Toprak S, Cetin I, Guven T, Can G, Demircan C (2011) Self-harm, suicidal ideation and suicide attempts among college students. Psychiatry Research 187:140-4 DOI 10.1016/j.psychres.2010.09.009

22. Ilias I, Alesci S, Gold PW, Chrousos GP (2006) Depression and Osteoporosis in Men: Association or Casual Link? Hormones 5:9-16

23. Minns Lowe CJ, Toye F, Barker KL (2019) Men's experiences of having osteoporosis vertebral fractures: a qualitative study using interpretative phenomenological analyses. Osteoporosis International 30:1403-12

24. Solimeo SL (2011) Living with a 'women's disease': risk appraisal and management among men with osteoporosis. Journal of Men's Health 8:185-91 
25. Solimeo SL, Weber TJ, Gold DT (2011) Older Men's Explanatory Model for Osteoporosis. The Gerontologist 51:530-9

26. Taylor B (2003) Exploring the perspectives of men who self-harm. Learning in Health and Social Care 2:83-91

27. National Osteoporosis Guideline Group (2017) NOGG 2017: clinical guideline for the prevention and treatment of osteoporosis.

28. van Schoor NM, Smit JH, Twisk JWR, Lips P (2005) Impact of vertebral deformities, osteoarthritis, and other chronic diseases on quality of life: a population-based study. Osteoporos Int 16:749-56 DOI $10.1007 /$ s00198-004-1744-9

29. Sanfélix-Genovés J, Hurtado I, Sanfélix-Gimeno G, Reig-Molla B, Peiró S (2011) Impact of osteoporosis and vertebral fractures on quality-of-life. a population-based study in Valencia, Spain (The FRAVO Study). Health and Quality of Life Outcomes 9:20

30. Alexandru D, So W (2012) Evaluation and Management of Vertebral Compression Fractures. Perm J 16:46-51

31. Van Staa TP, Abenhaim L, Cooper C, Zhang B, Leufkens HG (2000) The use of a large pharmacoepidemiological database to study exposure to oral corticosteroids and risk of fractures: validation of study population and results. Pharmacoepidemiol Drug Saf 9:359-66 DOI 10.1002/10991557(200009/10)9:53.0.CO;2-E

32. Cooper C, Atkinson EJ, O'Fallon WM, Melton JL (2019) Incidence of clinically diagnosed vertebral fractures: A population-based study in Rochester, Minnesota, 1985-1989. Journal of Bone and Mineral Research 7:221-7

33. Morley J, Moayyeri A, Ali L, Taylor A, Feudjo-Tepie M, Hamilton L, Bayly J (2020) Persistence and compliance with osteoporosis therapies among postmenopausal women in the UK Clinical Practice Research Datalink. Osteoporos Int 31:533-45 DOI 10.1007/s00198-019-05228-8

\section{Tables}

Table 1: Characteristic of patients with vertebral fracture and their matched cohorts (1990-2016) 


\begin{tabular}{|c|c|c|}
\hline Factor & Exposed (\%) & Unexposed (\%) \\
\hline $\mathrm{N}$ & 16,293 & 16,293 \\
\hline Mean age at index (SD) & $74.84(10.7)$ & $74.31(11.2)$ \\
\hline Females & $11,549(70.1)$ & $11,549(70.1)$ \\
\hline Median years follow-up (IQR) & $4.1(2.3,7.1)$ & $4.8(2.5 .8 .7)$ \\
\hline \multicolumn{3}{|l|}{ Deprivation status } \\
\hline Q1 (Least deprived) & $3763(23.1)$ & $3059(18.8)$ \\
\hline Q2 & $2911(17.9))$ & $2786(17.1)$ \\
\hline Q3 & $2947(18.1)$ & 3335 (20.5) \\
\hline Q4 & $3284(20.1)$ & $3603(22.1)$ \\
\hline Q5 (Most deprived) & $3388(20.8)$ & $3510(21.5)$ \\
\hline \multicolumn{3}{|l|}{$\mathrm{BMI}\left(\mathrm{kg} / \mathrm{m}^{2}\right)$} \\
\hline Underweight (<18.5) & $590(3.6)$ & $136(0.8)$ \\
\hline Healthy weight $(<18.5-24.9)$ & $6036(37.1)$ & $2136(13.1)$ \\
\hline Overweight (25.0-29.9) & $4955(30.4)$ & $2213(13.6)$ \\
\hline Obese $(>30.0)$ & $2467(15.1)$ & $1267(7.8)$ \\
\hline Missing & $2245(13.8)$ & $10,541(64.7)$ \\
\hline \multicolumn{3}{|l|}{ Smoking } \\
\hline Never/Ex smoked & $5656(34.7)$ & $12,908(79.2)$ \\
\hline Current smoker & $962(5.9)$ & $2373(14.6)$ \\
\hline Missing & $9675(59.4)$ & $1012(6.2)$ \\
\hline \multicolumn{3}{|l|}{ Alcohol consumption } \\
\hline Never/Ex-drinker & $1719(10.6)$ & $3881(23.8)$ \\
\hline Current 1-9 & $3387(20.8)$ & 7879 (48.4) \\
\hline Current $>=10$ & $663(4.1)$ & $2240(13.7)$ \\
\hline Missing & $10,524(64.6)$ & $2293(14.1)$ \\
\hline Anxiety & $3350(20.6)$ & 1690 (10.4) \\
\hline Depression & $4505(27.7)$ & $2330(14.3)$ \\
\hline
\end{tabular}


Table 2: Risk of self-harm associated with vertebral fracture

\begin{tabular}{|c|c|c|c|c|c|c|}
\hline \multirow{3}{*}{ Condition } & \multicolumn{2}{|c|}{ Exposed } & \multicolumn{2}{|c|}{ Non-exposed } & \multicolumn{2}{|c|}{ Hazard ratios $(95 \% \mathrm{Cl})$} \\
\hline & $\mathrm{n}$ & $\begin{array}{l}\text { Incidence rate, } \\
\text { per }\end{array}$ & $\mathrm{n}$ & $\begin{array}{l}\text { Incidence rate, } \\
\text { per }\end{array}$ & Crude & Adjusted* \\
\hline & & $10,000(95 \% \mathrm{Cl})$ & & $10,000(95 \% \mathrm{Cl})$ & & \\
\hline Total & 104 & $12.2(10.1,14.8)$ & 51 & $5.1(3.9,6.7)$ & $\begin{array}{l}2.3 \\
(1.7,3.3)\end{array}$ & $\begin{array}{l}2.4(1.5, \\
3.6)\end{array}$ \\
\hline \multicolumn{7}{|l|}{ Age } \\
\hline $\begin{array}{l}\text { Younger } \\
(<76.3)\end{array}$ & 63 & $13.4(10.4,17.1)$ & 25 & $4.3(2.9,6.4)$ & $\begin{array}{l}3.1(1.9 \\
4.8)\end{array}$ & $\begin{array}{l}3.2(1.8, \\
5.7)\end{array}$ \\
\hline Older $(=>76.3)$ & 41 & $10.8(8.0,14.7)$ & 26 & $6.1(4.2,9.0)$ & $\begin{array}{l}1.7(1.0, \\
2.7)\end{array}$ & $\begin{array}{l}1.7(0.9 \\
3.3)\end{array}$ \\
\hline \multicolumn{7}{|l|}{ Gender } \\
\hline Male & 41 & $17.1(12.6,23.2)$ & 12 & $4.2(2.4,7.3)$ & $\begin{array}{l}4.0(2.1, \\
7.7)\end{array}$ & $\begin{array}{l}3.9 \\
8.5)\end{array}$ \\
\hline Female & 63 & $10.3(8.1,13.2)$ & 39 & $5.4(4.0,7.5)$ & $\begin{array}{l}1.8(1.2, \\
2.7)\end{array}$ & $\begin{array}{l}1.9(1.1, \\
3.2)\end{array}$ \\
\hline
\end{tabular}

*adjusted for age, BMI, smoking status, alcohol consumption, anxiety, depression and practice-level deprivation. Bold $=$ statistically significant $(p<=0.05)$. 